\title{
EVALUATION OF $\mathrm{O}_{2}$ PLASMA AND $\mathrm{XeF}_{2}$ VAPOR ETCH RELEASE PROCESSES FOR RF-MEMS SWITCHES FABRICATED USING CMOS INTERCONNECT TECHNOLOGY
}

\author{
Christopher V. Jahnes, Nils Hoivik, John M. Cotte, Minhua Lu, and John H. Magerlein \\ IBM T. J. Watson Research Center \\ Yorktown Heights, NY 10598
}

\begin{abstract}
This paper evaluates two commercially available dry etch processes for releasing integrated RF MEMS devices. The first is an oxygen microwave plasma removal of a Diamond-Like Carbon (DLC) sacrificial layer and the second is a $\mathrm{XeF}_{2}$ vapor phase removal of an amorphous silicon (a-Si) sacrificial layer. The studied techniques were selected for compatibility in fabricating monolithically integrated RF-MEMS devices within the interconnect levels of CMOS and Bi-CMOS technologies. To determine the etch rate of the sacrificial release layer, test wafers were fabricated using a simple 1-mask lithography level that allows direct observation of the release etch through a dielectric membrane. Effects relating to changes in the release etch rate are documented and discussed. Additionally, the ability of $\mathrm{XeF}_{2}$ to extract sacrificial layers through small via holes, and bulk vs. thin-film etching of a-Si for MEMS release etches are presented. The results of this study demonstrate that both oxygen microwave plasma removal of DLC and $\mathrm{XeF}_{2}$ vapor phase etch of a-Si can be used to manufacture RF-MEMS devices using high volume CMOS interconnect manufacturing processes.
\end{abstract}

\section{INTRODUCTION}

A common process element in the fabrication of MEMS devices is the removal of a sacrificial layer to release the micromechanical device from a substrate. Ideally the release process removes the sacrificial layer quickly and cleanly without altering the micromechanical element. In a more specific application, such as integrating RF-MEMS devices in CMOS interconnect levels [1-2], the release process must also not degrade the existing structure or devices. While many processes exist to remove sacrificial layers [3], we have studied $\mathrm{XeF}_{2}$ etching of $\mathrm{Si}$ sacrificial layers and $\mathrm{O}_{2}$ microwave plasma etching of DiamondLike-Carbon (DLC) sacrificial layers. Both of these techniques work well in the aforementioned application where the sacrificial layer is typically less than $1.0 \mu \mathrm{m}$ thick and the micromechanical beam is primarily $\mathrm{SiO}_{2}$. In addition, $\mathrm{Si}$ and DLC are compatible with CMOS fabrication lines and can be deposited by many different techniques. The commercially available process tools used to perform the release etch are an Applied Materials APS + chamber for the $\mathrm{O}_{2}$ microwave plasma process and a Xactix X3 Xetch ${ }^{\circledR}$ system.

The efficiency of the release etch can be influenced by geometric relationships that evolve as micromechanical structures are being released. Even small displacements of the micromechanical beams during the release etch can have significant effects. In this report we have fabricated structures to facilitate evaluation of both $\mathrm{XeF}_{2}$ and $\mathrm{O}_{2}$ microwave plasma release etching processes. The test devices were made identical to compare the two processes and gain a general understanding of the etch behavior. Structures to evaluate release etching of a sacrificial layer through via holes and of bulk Si sacrificial layer etching were also explored. For demonstration purposes, fully integrated RF-MEMS CMOS integrated switches were fabricated and tested to verify compatibility of these processes with interconnect structures. Both techniques resulted in MEMS switches with insertion loss $<0.5 \mathrm{~dB}$.

\section{EXPERIMENTAL DETAILS}

The test samples used to evaluate the two release etch processes are shown in Figure 1 with optical photographs of an example device before and after the release etch. The fabrication process for these samples is as follows: for the a-Si release samples, the Si wafer is first thermally oxidized to form a $100 \mathrm{~nm}$ thick $\mathrm{SiO}_{2}$ layer to protect the $\mathrm{Si}$ wafer from being etched in the $\mathrm{XeF}_{2}$ process. For the DLC samples the thermal oxide layer was not required. The next step is to form the sacrificial layer which for DLC was deposited by PECVD with post $400{ }^{\circ} \mathrm{C}$ annealing and the a-Si samples were deposited by DC sputtering. After the sacrificial layer deposition, the dielectric membrane was deposited. For the a-Si release structures a single layer of PECVD $\mathrm{SiO}_{2} 1000 \mathrm{~nm}$ thick was deposited at $400^{\circ} \mathrm{C}$. In the case of the DLC a sandwich structure of $\mathrm{SiN} 35 \mathrm{~nm} / \mathrm{SiO}_{2} 1000 \mathrm{~nm} / \mathrm{SiN} 35 \mathrm{~nm}$ was deposited by PECVD at $400^{\circ} \mathrm{C}$. $\mathrm{SiN}$ is required to gain good adhesion between the DLC and $\mathrm{SiO}_{2}$. To minimize stress distortion a top layer of SiN was added to "balance" the stress gradient of the structure. Lastly, the samples are coated and patterned with photoresist, etched with RIE to open the dielectric stack down to the release layer and the resist is then stripped in-situ with an $\mathrm{O}_{2}$ plasma. The $\mathrm{O}_{2}$ resist strip process does remove the DLC in the open areas but is timed such that no detectable undercut occurs.

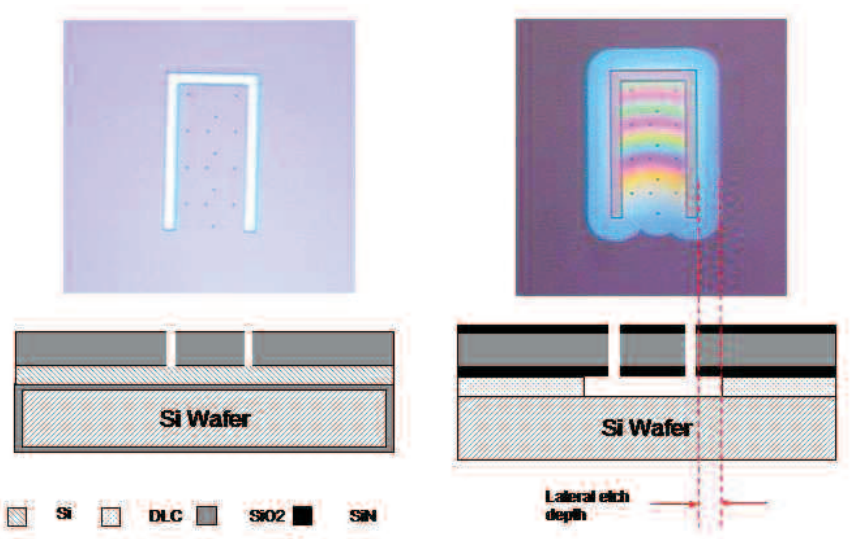

Figure 1. Top: Optical photos of structures prior to release (left) and after release (right). Bottom: Schematic view of silicon test vehicle (left) and DLC release (right). 


\section{$\mathrm{O}_{2}$ MICROWAVE PLASMA RELEASE ETCH}

An Applied Materials APS+ microwave strip chamber was used to perform the $\mathrm{O}_{2}$ microwave plasma release etches. The chamber uses IR lamps to directly heat the wafer which is placed slightly downstream of the waveguide that introduces the microwave into the chamber [4]. Key advantages to this platform for etching are the lack of ion bombardment to minimize sputtering effects and the application of heat to enhance the etch rate of the DLC. In these experiments wafer pieces were used and placed on a $200 \mathrm{~mm}$ wafer to allow for simultaneous processing on different structures. In all cases the gas chemistry was kept constant $\left(\mathrm{O}_{2} 3000 \mathrm{sccm}\right.$ and $\left.\mathrm{N}_{2} 200 \mathrm{sccm}\right)$ at a total pressure of 2 Torr.

Two sets of samples were fabricated to optimize the $\mathrm{O}_{2}$ microwave plasma release process. The first set was made with a $300 \mathrm{~nm}$ DLC sacrificial layer. After release, the membrane was under slight tensile stress, and had very little stress related distortion. In the second set of samples, a range of DLC thicknesses was deposited (100 nm. $200 \mathrm{~nm}, 400 \mathrm{~nm}$ and $800 \mathrm{~nm}$ ) to evaluate the release etch rate as a function of sacrificial layer thickness. However, the dielectric membrane for these samples was deposited using a different PECVD reactor and upon release were found to have highly distorted membranes. This was later determined to be from a temperature variation during the PECVD $\mathrm{SiO}_{2}$ deposition that increased the compressive stress of the dielectric membrane and added a negative stress gradient within the $\mathrm{SiO}_{2}$ layer.

As a result, upon release the membrane deflected downward towards the substrate, as shown for the device in Figure 2A. This deformation effectively narrows the release gap and causes an uneven removal of the sacrificial layer. High temperature annealing $\left(450{ }^{\circ} \mathrm{C}\right)$ was used to minimize the stress magnitude and gradient to the point where the etch front was uniform. The stress effects were still apparent however as shown in Figure 2B. For comparison the device shown in Figure $2 \mathrm{C}$ is from the first sample set with a $3000 \mathrm{~nm}$ DLC sacrificial layer, and with a slightly tensile membrane and no stress gradient. White light interferometric measurements were used to measure the membrane deflection at mid length of the cantilever for samples after $10 \mathrm{~min}$ $\mathrm{O}_{2}$ microwave plasma etch. A deflection of $10 \mathrm{~nm}$ to $50 \mathrm{~nm}$ towards the substrate was observed for the set of samples with stress related distortions, and no deflection was detected for the sample that was free of stress related distortions.

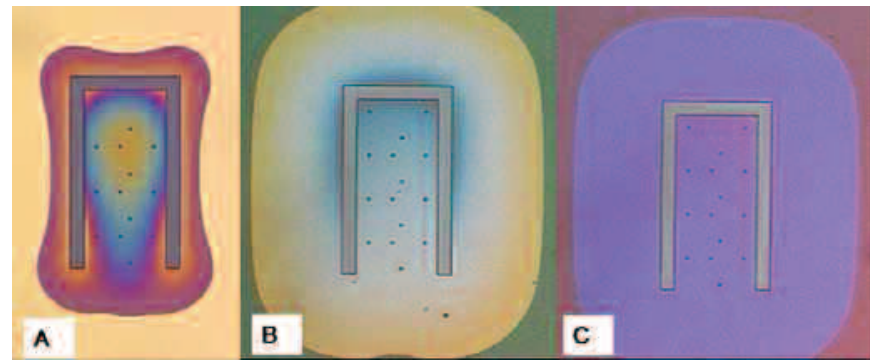

Figure 2. Optical photograph of released test samples (cantilever $27 \mu \mathrm{m} \times 60 \mu \mathrm{m}$ ). Deformations in A shows a highly stressed membrane with uneven release front in as-deposited membrane. After annealing, sample B (with a $400 \mathrm{~nm} D L C$ sacrificial layer) demonstrates a reduced compressive stressed membrane. Sample C has a $300 \mathrm{~nm}$ DLC sacrificial layer, tensile membrane with no stress gradient and no stress related distortion.
To optimize the $\mathrm{O}_{2}$ microwave release process, wafer temperature and microwave power were varied. Shown in Figure 3 is a plot of the lateral undercut depth as a function of wafer temperature. As expected, the etch rate increases rapidly with increasing temperature, reaching rates as high as $6 \mu \mathrm{m} / \mathrm{min}$. All the samples appear to have equal release etch rates until temperatures above $250{ }^{\circ} \mathrm{C}$. The difference in lateral etch rate at higher temperatures may be due to diffusion limiting effects. In addition, deflection in the released membrane, which is larger for these deep undercuts, may play a significant role.

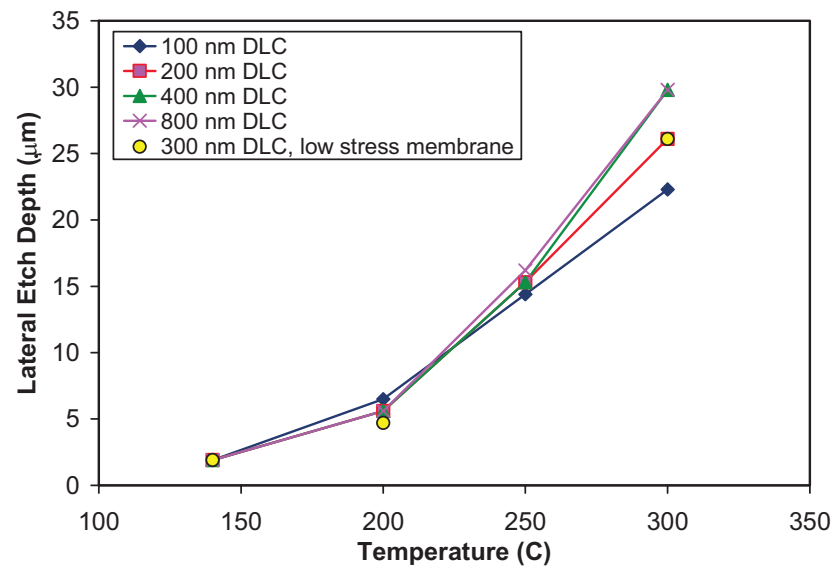

Figure 3. Plot of lateral etch depth vs. wafer temperature during $\mathrm{O}_{2}$ plasma microwave release at $1400 \mathrm{~W}$ for a 5 min. release etch.

The effect of microwave power on the release etch rate is shown in Figure 4. A near linear increase in rate was observed up to 500 $\mathrm{W}$, after which the release etch rate slowed and eventually remained constant. At this point the plasma may be at a critical density and not increase [5]. Another possible explanation for the release rate to level off would be if physical sputtering were occurring, acting as to mask the release layer. However no $\mathrm{SiO}_{2}$ loss was observed for a $25 \mathrm{~min} 1400 \mathrm{~W}$ etch.

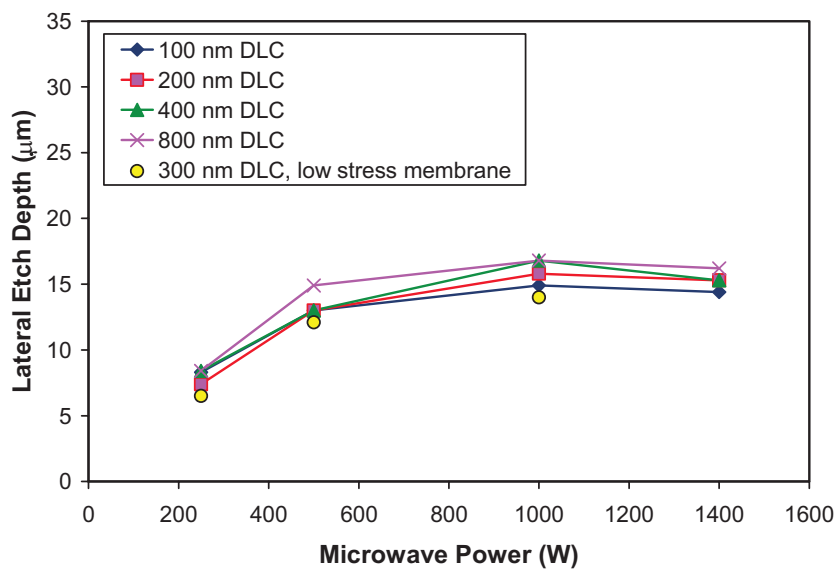

Figure 4. Plot of release etch vs. microwave power for $\mathrm{O}_{2}$ microwave plasma etch at $250^{\circ} \mathrm{C}$ for $5 \mathrm{~min}$. 


\section{$\mathrm{XeF}_{2}$ RELEASE ETCH}

All Si etching experiments were performed using an $\mathrm{X} 3$ Series $\mathrm{XeF}_{2}$ etching system manufactured by Xactix [6]. The $\mathrm{XeF}_{2}$ etching is a gas phase process with no plasma and is performed at room temperature (although the Si etching process is exothermic in nature [7]). The $\mathrm{XeF}_{2}$ release etch is a cyclical process where $\mathrm{XeF}_{2}$ gas is introduced into a process chamber, allowed to react for a pre-determined dwell time, and pumped out. Gas pressure is established in a separate expansion chamber prior to introduction into the process chamber. The process chamber pressure is 3.4 times lower than the pressure reported here which is measured in the expansion chamber. The amount of Si etched can be controlled by the number of pulses, as well as $\mathrm{XeF}_{2}$ pressure and concentration using $\mathrm{N}_{2}$ as a dilutant. The samples etched for each experiment had Si exposed over $1.6 \%$ of the top surface dielectric area, and were $2 \times 2 \mathrm{~cm}$ chips with the Si wafer edge exposed (a total of $0.66 \mu^{2}$ ). The a-Si sacrificial layers were 100, 200, 400, 600,800 or $1000 \mathrm{~nm}$ thick. These samples were also annealed at $450{ }^{\circ} \mathrm{C}$ prior to release to reduce the as-deposited stress gradient. After release, the deflection for a $60 \mu \mathrm{m}$ long cantilever was $\sim 1$ $\mu \mathrm{m}$.

Due to the large selectivity between $\mathrm{Si}$ and $\mathrm{SiO}_{2}$, all samples were etched in DHF $(100: 1)$ for $15 \mathrm{sec}$ followed by a DI water rinse to remove any native oxide from the Si layer. Samples which did not receive this pre-processing step required an additional 2030 cycles of $\mathrm{XeF}_{2}$ in order to break through the native oxide before any etch could be observed [7]. The etch rate of thermal $\mathrm{SiO}_{2}$ was measured to be $\sim 60 \mathrm{~A}$ for 20 cycles with $1.5 \mathrm{~T} \mathrm{XeF}_{2}$ and $10 \mathrm{~T} \mathrm{~N} 2$.

To study the effect of $\mathrm{XeF}_{2}$ concentration on the release etch rate, two sets of samples were run at 1.5 and 3.0 Torr. A higher $\mathrm{XeF}_{2}$ concentration is expected to lead to a faster etch rate as illustrated in Figure 5. However the release etch rate increased far more than expected. It is known that the $\mathrm{XeF}_{2}$ etch is not $100 \%$ efficient [7] and this data suggests the efficiency is pressure dependent. The decrease in release rate at high pressure for thinner sacrificial layers is likely diffusion related. Similar dependencies on aperture vs. lateral etch depth for thin film etching were reported for 3 Torr $\mathrm{XeF}_{2}$ etches [7].

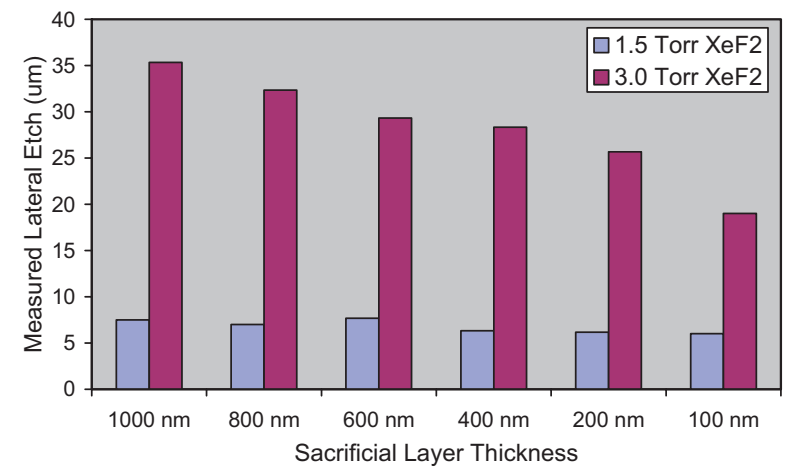

Figure 5. Measured lateral etch rate with varying $\mathrm{XeF}_{2}$ pressure. Both sets were run for 10 cycles, each $30 \mathrm{sec}$.

Lateral etch rate was also measured as a function of dwell time by varying the dwell time from 5 to $60 \mathrm{sec}$ for three sacrificial layer thicknesses. As seen in Figure 6, the amount of etching is relatively independent of dwell time. From this experiment is evident that the etch process happens in the first few seconds upon exposure of $\mathrm{Si}$ to $\mathrm{XeF}_{2}$. The independence of exposure time was also observed for samples etched with 3.0 Torr $\mathrm{XeF}_{2}$. This observation contradicts earlier reports on an increase in lateral etch of poly-Si with increasing pulse duration [7]. Furthermore, no pressure increase was observed in the process chamber during the etch process. As presented, this data supports a self-limiting effect or a reactant limited etch process. More experiments are in progress to determine this more accurately.



Figure 6. Measurement on effect of cycle time on lateral etch rate. The cycle time was varied between $5-60 \mathrm{sec}$. for 40 cycles 1.5 Torr $\mathrm{XeF}_{2}$.

Adding nitrogen to raise the process pressure resulted in an increase in overall release etch rate with a maximum observed for 10 Torr $\mathrm{N}_{2}$ and 1.5 Torr $\mathrm{XeF}_{2}$ as shown in Figure 7. The additional nitrogen pressure increased the reaction rate of the physisorbed $\mathrm{XeF}_{2}$ by as much as a factor of 3 while it also enhanced limited reactions.

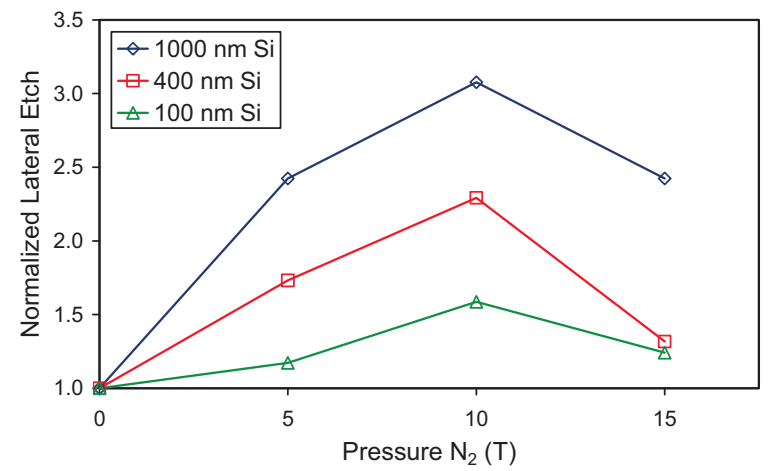

Figure 7. $\quad$ Measured normalized effect of $N_{2}$ pressure on lateral etch rate. Maximum etch rate is obtained for with $\mathrm{N}_{2}$ pressure of 10 Torr (10 cycles, $30 \mathrm{sec} 1.5$ Torr $\mathrm{XeF}_{2}$ )

To compare bulk Si etching, samples were prepared with a single layer of patterned thermal $\mathrm{SiO}_{2}$. Figure 8 shows a comparison between lateral etch rate for a thin film and bulk sacrificial layer. The lower undercut rate for a bulk release is not unexpected since more material is being removed, and should be factored in when releasing MEMS devices from a bulk Si-substrate. Thus, devices which depend on dielectrics and metals with low etch selectivity to Si should utilize a thin film over bulk release process as to minimize the exposure to $\mathrm{XeF}_{2}$. 


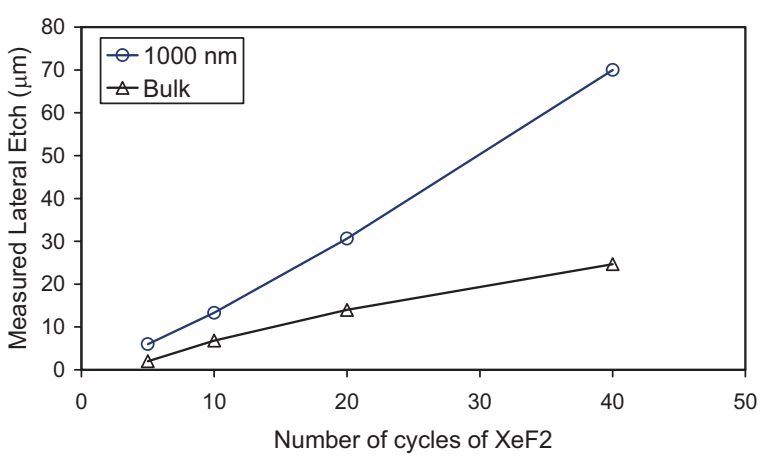

Figure 8. Comparison of lateral etch rate of a thin-film to a bulk release process. $30 \mathrm{sec}$ pulses, 1.5 Torr $\mathrm{XeF}_{2}-10$ Torr N2

\section{COMPARISON OF RELEASE PROCESSES}

Figure 9 shows a comparison between the $\mathrm{O}_{2}$ and $\mathrm{XeF}_{2}$ release process. For the $\mathrm{O}_{2}$ release process, the effective etch rate decreases with lateral etch depth. This is caused by the effective surface area increase of DLC as the release etch depth increases. The flux of excited $\mathrm{O}_{2}$ species entering the release area is determined by the geometry of the membrane cutout, which remains constant. Both release processes show a decrease in etch rate for a thin sacrificial layer, due to diffusion limitations and stress related deformation of the structural layer. It is important to note that most RF-MEMS devices typically need about $10 \mu \mathrm{m}$ to $20 \mu \mathrm{m}$ of a lateral etch to fully release all devices.

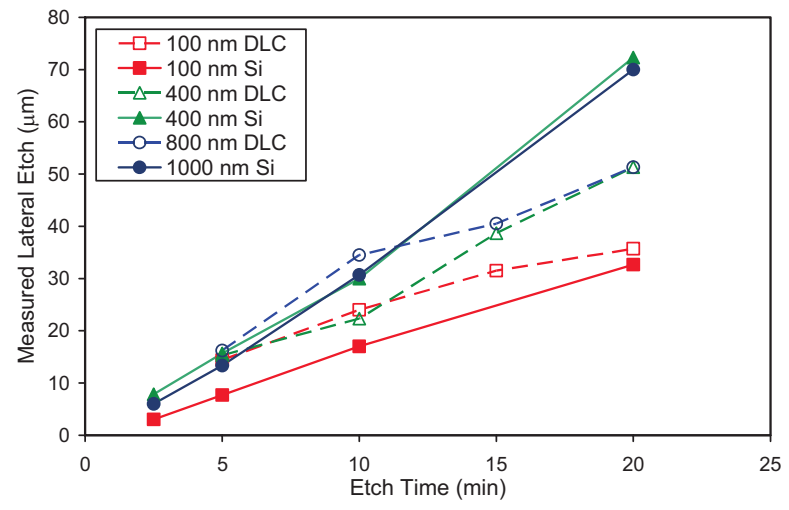

Figure 9. Comparison of lateral etch depth vs. etch time for a $250{ }^{\circ} \mathrm{C} 1400 \mathrm{~W} \mathrm{O}_{2}$ microwave plasma and $30 \mathrm{sec}$ pulsed 1.5 Torr $\mathrm{XeF}_{2}-10$ Torr $\mathrm{N}_{2}$ Si release process.

Release can also be carried out through a dielectric film with small holes, which may subsequently be pinched off for waferlevel packaging by thin-film encapsulation. This was previously described in detail for the DLC process using the $\mathrm{O}_{2}$ plasma release process [1]. Figure 10 shows SEM pictures of a sacrificial layer removal using $\mathrm{XeF}_{2}$ dry etch to extract a $300 \mathrm{~nm}$ thick a-Si film through $0.25 \mu \mathrm{m}$ diameter $\times 1.0 \mu \mathrm{m}$ tall holes in a $1 \mu \mathrm{m}$ thick $\mathrm{SiO}_{2}$ film.

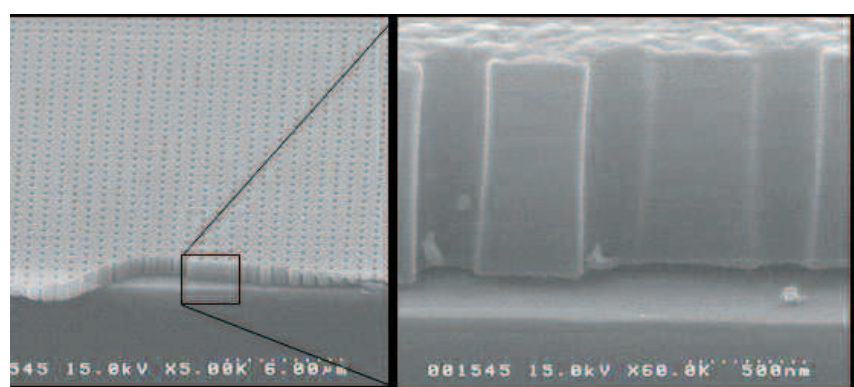

Figure 10. SEM image of cleaved sample of hole grid pattern for $\mathrm{XeF}_{2}$ a-Si release through a top dielectric layer with 0.25-um wide holes $1.0 \mu \mathrm{m}$ tall. The nominal gap is $300 \mathrm{~nm}$.

\section{SUMMARY}

The results of this study demonstrate that both $\mathrm{O}_{2}$ plasma removal of DLC and $\mathrm{XeF}_{2}$ vapor phase etch of a-Si can be used to manufacture RF-MEMS devices using high volume CMOS interconnect manufacturing processes. Both techniques can extract a sacrificial release layer through small vias, which is a requirement for thin-film encapsulation packaging of RF-MEMS devices at wafer level. For large lateral undercuts $(>20 \mu \mathrm{m}), \mathrm{XeF}_{2}$ is superior as compared to microwave plasma etching as the release rate decrease is less pronounced. Measured RF performance of ohmic switches fabricated both with DLC and Si release layers have demonstrated excellent RF characteristics.

\section{ACKNOWLEDGEMENTS}

The authors wish to thank Roy Carruthers and Blake Lin for sample preparation, and Kyle Lebouitz from Xactix Inc. and Glenn Laliberte from Applied Materials Corporation for their technical assistance with the commercial release etch process tools used for this study.

\section{REFERENCES}

[1] Jennifer L. Lund et al. "A Low Temperature Bi CMOS Compatible Process for MEMS rf Resonators and Filters", SolidState Sensor, Actuator and Microsystems Workshop, Hilton Head Island, June 2-6, 2002.

[2] C. V. Jahnes et al. "Simultaneous Fabrication of RF MEMS Switches and Resonators using Copper-based CMOS Interconnect Manufacturing Methods", MEMS 2004 Technical Digest, Jan 2529, pp $789-792$.

[3] Micromachined Transducers Sourcebook, 1 Edition 1998, Gregory T. Kovacs.

[4] www.appliedmaterials.com

[5] Thin Film Processes II, 1991, edited by John L. Vossen, Werner Kern.

[6] www.xactix.com

[7] Patrick B. Chu et al. "Controlled Pulse-Etching with Xenon Difluoride", Transducers 1997, Chicago June 16-19, pp 665 - 668. 